\title{
British-Russian workshop for young scientists: "Climate Change, the tree growth response, and reconstruction of climate"
}

KRASNOYARSK, RUSSIA; 25-29 JaNUARY 2006

From 25-29 January, young researchers from the UK and Russia came together in Krasnoyarsk at a workshop organized by the British Council, Russia (within the International Networking for Young Scientists program), in collaboration with the Climatic Research Unit (University of East Anglia, Norwich, UK; www.cru.uea.ac.uk) and the Sukachev Institute of Forest (Krasnoyarsk, Russia; http://forest.akadem.ru). The primary focus of the workshop was on dendroclimatology.

Over the last decade or so, the number of reconstructions of global, or more particularly Northern Hemisphere, temperature changes during the last $1000-2000$ years has proliferated, as the debate on the causes of recent warming has intensified. These new reconstructions, using variously selected combinations of proxy data and different statistical approaches in their interpretation, have one thing in common: they are all heavily dependent on the information provided by tree-ring data.

In the depths of a severe Siberian winter, students and young researchers, all working within this field, came together to make presentations describing their work and to hear lectures given by established researchers from the UK, USA and Russia. The talks and several round-table discussions focused on issues directly related to the need for tree-ring studies to provide realistic estimates of past climatic changes. The topics included:

- chronology construction methods and the preservation of long-timescale signals.

- tree-growth modeling techniques and their value in climate reconstruction

- statistical methods for identifying optimal climate forcing on tree growth

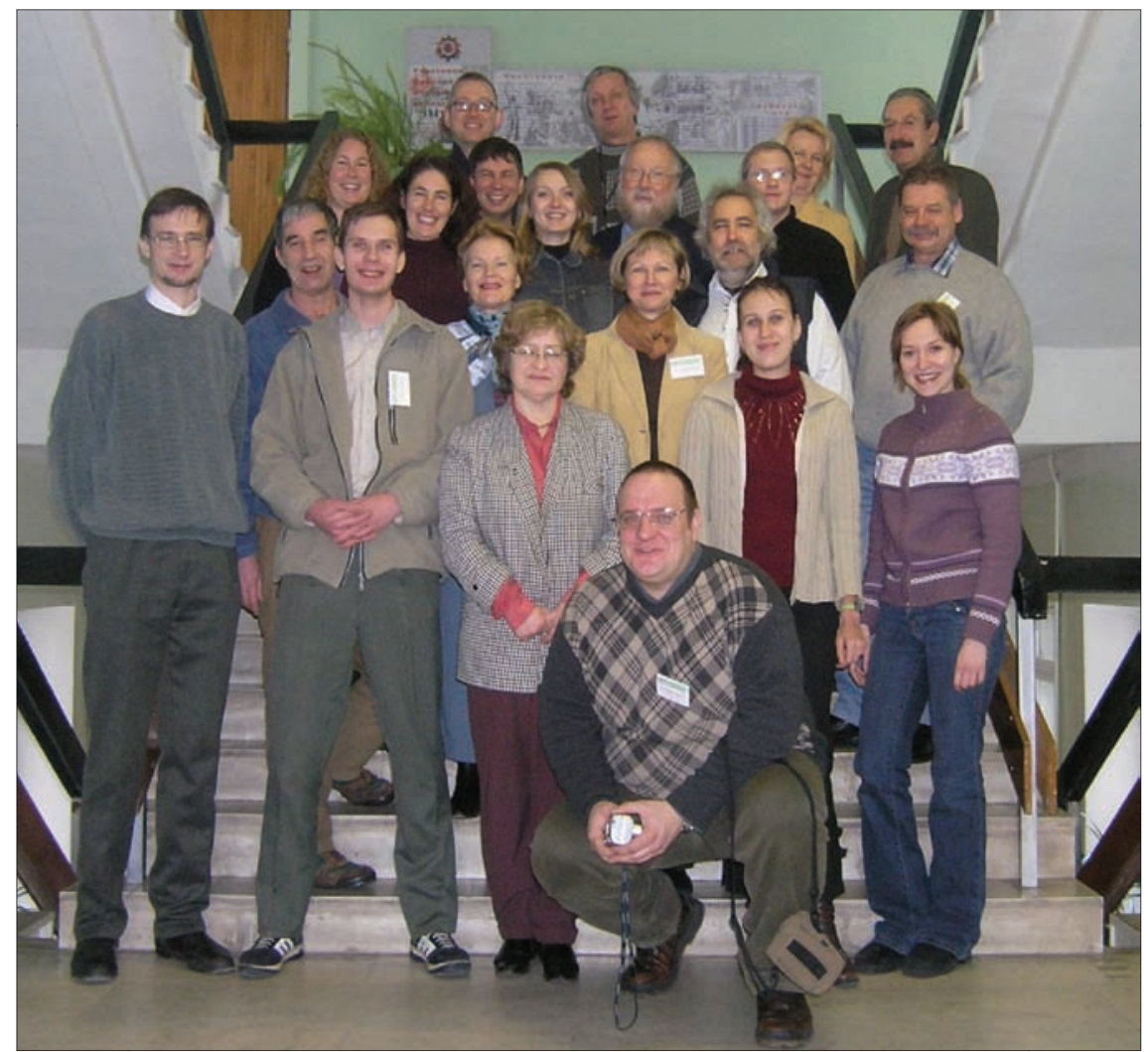

Fig. 1:Participants of the British-Russian workshop "Climate change, the tree growth response, and reconstruction of climate" (25 - 29 January 2006, Krasnoyarsk, Russia)

- synthesis of the evidence for climate change as derived from different tree-ring parameters (e.g. ring width, density and isotopic composition).

This meeting provided a rare opportunity to bring together young scientists from widely separated parts of the globe and with wideranging specialties, allowing them to re-examine their work in the context of climate change. It is hoped that it widened their horizons and suggested new approaches. It certainly broke down barriers and may even have initiated collaborations that will endure for many years to come.

\section{AcKnowledgments}

We wish to thank the British Council, Russia for their provision of funding and their assistance in the logistics required in the arrangement of this workshop. We also wish to thank PAGES for their provision of funding for visiting experts.

\section{VLAdimiR SHISHOV}

Sukachev Institute of Forset, Akademgorodok, Krasnoyarsk, Russia

shishov@forest.akadem.ru

\section{KeIth BRIfFA}

University of East Anglia, Norwich, UK k.briffa@uea.ac.uk

\section{Tom Melvin}

University of East Anglia, Norwich, UK t.m.melvin@uea.ac.uk 